\title{
The Effectiveness of Cross-Tapering Switching to Ziprasidone in Patients with Schizophrenia or Schizoaffective Disorder
}

\author{
Young-Hoon $\mathrm{Ko}^{1 *}$, Kyoung-Sae $\mathrm{Na}^{2 *}$, Chul-Eung Kim${ }^{3}$, Seung-Hyun Kim${ }^{4}$, Yang-Whan Jeon ${ }^{5}$, Jung-Seo $\mathrm{Yi}^{6}$, \\ Moon-Soo Lee ${ }^{5}$, Shin-Gyeom Kim ${ }^{7}$, Hyun-Ghang Jeong ${ }^{5}$, and Han-Yong Jung ${ }^{7}$ \\ 1Department of Psychiatry, Korea University College of Medicine, Ansan Hospital, Ansan, Republic of Korea \\ ${ }^{2}$ Department of Psychiatry, Gachon University Gil Medical Center, Incheon, Republic of Korea \\ ${ }^{3}$ Department of Psychiatry, Inha University Hospital, Incheon, Republic of Korea \\ ${ }^{4}$ Department of Psychiatry, Korea University College of Medicine, Guro Hospital, Seoul, Republic of Korea \\ ${ }^{5}$ Department of Psychiatry, Incheon St. Mary's Hospital, The Catholic University of Korea College of Korea, Incheon, Republic of Korea \\ ${ }^{6}$ Department of Psychiatry, Hallym University College of Medicine, Kangnam Sacred Heart Hospital, Seoul, Republic of Korea \\ ${ }^{7}$ Department of Psychiatry, Soonchunhyang University College of Medicine, Bucheon Hospital, Bucheon, Republic of Korea
}

Objective Switching antipsychotics is one useful therapeutic option when the treatment of schizophrenia encounters suboptimal efficacy and intolerability issues. This study aimed to investigate the efficacy and tolerability of cross-tapering switching to ziprasidone from other antipsychotics.

Methods A total of 67 patients with schizophrenia or schizoaffective disorder were recruited in this 12-week, multicenter, non-comparative, open-label trial. Prior antipsychotics were allowed to be maintained for up to 4 weeks during the titration of ziprasidone. Efficacy was primarily measured using the 18-item Brief Psychotic Rating Scale (BPRS) at baseline, 4 weeks, 8 weeks, and 12 weeks. Efficacy was secondarily measured by the Clinical Global Impression-Severity (CGI-S) scale and the Global Assessment of Functioning (GAF) scale at each visit. Regarding the metabolic effects of switching to ziprasidone, weight, body mass index (BMI), waist-to-hip ratio (WHR), and lipid profile-including triglyceride (TG), high-density lipoprotein (HDL), low-density lipoprotein (LDL), and total cholesterol levels-were measured at each follow-up visit.

Results The BPRS scores were significantly improved at 12 weeks after switching to ziprasidone $(\mathrm{F}=5.96, \mathrm{df}=2.11, \mathrm{p}=0.003)$, whereas the CGI-S and GAF scores were not significantly changed. BMIs, WHRs, and TG levels were significantly decreased, with no significant changes in other lipid profiles.

Conclusion Cross-tapering switching to ziprasidone is effective for patients with schizophrenia spectrum disorders. Beyond the efficacy of the procedure, favorable metabolic profiles show that switching to ziprasidone may be helpful for maintenance therapy over an extended period.

Psychiatry Investig 2014;11(4):459-466

Key Words Ziprasidone, Schizophrenia, Switching, Pharmacotherapy, Triglyceride.

\section{INTRODUCTION}

Schizophrenia is a debilitating mental disease characterized by a waxing and waning course with substantial psychosocial impairment. ${ }^{1}$ It is necessary to maintain pharmacotherapy for

Received: January 27, 2014 Revised: May 4, 2014

Accepted: May 14, 2014 Available online: October 20, 2014

$\triangle$ Correspondence: Han-Yong Jung, MD, PhD

Professor, Department of Psychiatry, Soonchunhyang University Bucheon Hospital, 170 Jomaru-ro, Wonmi-gu, Bucheon 420-767, Republic of Korea

Tel: +82-32-621-5232, Fax: +82-32-621-6950, E-mail: hanyjung@schmc.ac.kr

*These authors contributed equally to this work.

(a) This is an Open Access article distributed under the terms of the Creative Commons Attribution Non-Commercial License (http://creativecommons.org/licenses/bync/3.0) which permits unrestricted non-commercial use, distribution, and reproduction in any medium, provided the original work is properly cited. this population, although psychosocial and preventive approaches should be used adjunctively. Because more than $70 \%$ of patients with schizophrenia discontinue their antipsychotics within 18 months due to suboptimal efficacy and/or intolerability, ${ }^{2}$ switching antipsychotics is an effective strategy for patients facing these issues. ${ }^{3}$ Because the effectiveness of antipsychotics has been shown to be similar, with the exception of clozapine, ${ }^{2}$ tolerability and safety have been increasingly regarded as one of the important determinants for selecting antipsychotics for patients with schizophrenia. Whereas extrapyramidal symptoms were issues of considerable concern with the use of typical antipsychotics, metabolic disturbances, such as obesity and hyperlipidemia, are perhaps the most burdensome factors in the era of atypical antipsychotics. ${ }^{4}$ 
Ziprasidone has high affinity for 5-HT receptors as well as for dopamine D2 receptors. Therefore, it has been shown to be effective for the treatment of positive and negative symptoms in schizophrenia and is associated with a lower potential for extrapyramidal symptoms. Moreover, recent studies have shown that ziprasidone (together with aripiprazole) has the most favorable metabolic profile. ${ }^{5}$ compared with other atypi$\mathrm{cal}$ antipsychotics. Therefore, for patients suffering from suboptimal efficacy and intolerability with current antipsychotics, ziprasidone might be a good alternative. As with other atypical antipsychotics, however, the optimal switching technique with respect to side-effect profiles and effectiveness has not been well established. Although recent studies have shown that there is no difference among the switching strategies used for ziprasidone, expert consensus guidelines prefer overlapped switching methods. ${ }^{6}$ However, additional data on the implementation of strategies for switching to ziprasidone are needed.

This study was designed with the aim of evaluating the clinical effectiveness of overlapping or cross-tapering switching to ziprasidone from other antipsychotics-including both atypical and typical antipsychotics-in Korean patients with schizophrenia or schizoaffective disorders.

\section{METHODS}

\section{Participants}

This study was a 12-week open-label, multi-center, prospective, non-comparative study conducted between November 2010 and March 2013. Patients aged 18-55 who were diagnosed with schizophrenia or schizoaffective disorder according to the Diagnostic and Statistical Manual of Mental Disorders, fourth edition (DSM-IV) ${ }^{7}$ were eligible to participate in the study. The patients were judged to require a change from their current antipsychotics; their primary psychiatric clinician determined that the patients would benefit from changes in their medications either because of suboptimal efficacy or because of side effects. Exclusion criteria were as follows: being a pregnant or lactating woman or being a woman with childbearing potential who was not using an acceptable method of contraception; having any other Axis I DSM-IV diagnosis; being treated with medications that prolong the QTc interval; having clinically significant abnormal laboratory values or any other abnormal baseline laboratory findings, such as EKG abnormalities, considered by psychiatrists to be indicative of conditions that might affect the study results; having a history of substance abuse or dependence within the last month; having a past history of hypersensitivity or intolerance to ziprasidone; having a history of clozapine use within the last month; having participated in clinical trials within 1 month prior to entering the study; having used depot antipsychotics within one cycle prior to entering the study; having an immediate risk of harming oneself or others or having a history of suicide attempts in the year prior to the screening.

Written informed consent was obtained from each patient before he or she entered the study. This study was conducted in compliance with the ethical principles originating in and derived from the Declaration of Helsinki and was in compliance with all International Conference on Harmonization Good Clinical Practice Guidelines. The final protocol, amendments, and informed consent were reviewed and approved by the institutional review boards at each of the investigational centers (ClinicalTrials.gov Identifier: NCT01198353).

\section{Dosing and switching strategies}

During the 12-week study period, patients were prescribed ziprasidone at 20 to $160 \mathrm{mg}$ /day flexibly based on their effectiveness and tolerability. Fifty to one hundred percent of the past antipsychotic dose was maintained in the first week; during next 3 weeks, flexible dosing of $0-100 \%$ was used; then, ziprasidone was discontinued. This study included four visits: baseline, week 4 , week 8 , and week 12 . Concomitant benzodiazepines (oral formula or injection) were allowed up to a dose of $4 \mathrm{mg}$ of lorazepam-equivalents per day for anxiety and agitation. Zolpidem could be used for insomnia. Drugs for extrapyramidal symptoms (EPS) were also allowed when needed but could not be used prophylactically. Mood stabilizers and antidepressants were permitted with fixed doses if they had been taken prior to enrollment. Other psychiatric drugs were not permitted during the study period.

\section{Outcome measures}

Efficacy was measured using the 18-item Brief Psychotic Rating Scale (BPRS). Efficacy was secondarily measured using the Clinical Global Impression-Severity (CGI-S) scale and the Global Assessment of Functioning (GAF) scale at baseline, 4 weeks, 8 weeks, and 12 weeks.

Regarding tolerability associated with metabolic issues, a lipid profile including triglyceride (TG), high-density lipoprotein (HDL), low-density lipoprotein (LDL), and total cholesterol levels, weight, body-mass index (BMI), and waist-to-hip ratio (WHR) were measured at baseline and at each followup visit.

\section{Safety measures}

Laboratory tests, physical examinations, vital signs measurements, and electrocardiograms were carried out at the baseline and 12-week visits. Adverse events were recorded at each visit using Udvalg for Kliniske Undersogelser Side Effect 
Rating Scale - Patient (UKU-SERS-Pat). ${ }^{8}$ The UKU-SERS-Pat items were divided into four side-effect subgroups: 1) psychic (e.g., concentration difficulties, asthenia, sleepiness, failed memory, depression, tension, change in sleep duration, increased dreaming, and emotional indifference); 2) neurologic (e.g., dystonia, rigidity, hypokinesia, hyperkinesia, tremor, akinesia, epileptic seizures, paresthesia, and headache); 3) autonomic (e.g., accommodation disturbances, change in salivation, nausea/vomiting, diarrhea, constipation, micturition disturbance, polyuria/polydipsia, orthostatic dizziness, palpitation, and sweating); and 4) others (e.g., rash, pruritus, photosensitivity, pigmentation, weight change, menorrhagia, metrorrhagia, amenorrhea, galactorrhea, gynecomastia, change in sexual desire, erectile dysfunction, ejaculatory dysfunction, premature ejaculation, orgasmic dysfunction, and dry vagina).

\section{Statistical analysis}

Sample size was calculated in accordance with the method used in a previous study involving a 12 -week switch to ziprasidone. ${ }^{9}$ In that study, when switching from olanzapine to ziprasidone, the mean change of BPRS scores from baseline to the endpoint was approximately five. We assumed that the SDs at baseline and the endpoint were 12.5 and 10.5, respectively. Assuming a drop-out rate of $40 \%$ with the required power of 0.80 and an overall type-I error rate of $0.05,45$ evaluable subjects were calculated to be necessary. Assuming a drop-out rate of $30 \%$, a total of 65 patients were expected to be recruited. Analyses were made on an intention-to-treat (ITT) basis, including all patients who had received at least one dose of ziprasidone and for whom at least one efficacy assessment was available using the last observation carried forward (LOCF) approach; an analysis of the completers was also performed for a consistency check. The significance of the change in efficacy measures from baseline was analyzed using a repeated-measures analysis of variance. A Greenhouse-Geisser correction was used to test for non-sphericity. A Fisher's exact test or a chi-square test was used for nominal data, whereas an independent $t$-test was used for continuous variables. All tests were 2 -tailed, and a probability value $<0.05$ was used to indicate statistical significance. All data were analyzed using PASW Statistics version 20 statistical software (PASW IBM Corp, Armonk, NY, USA).

\section{RESULTS}

\section{Participants}

The demographic and clinical characteristics at baseline are described in Table 1. Of the 67 patients enrolled, 25 patients dropped out of the study. Their reasons for dropping out were as follows: eight patients withdrew consent, seven patients were lost to follow-up, five patients discontinued their medication due to non-psychiatric adverse events, and five patients dropped out due to aggravation of their psychotic symptoms. Ultimately, 42 patients (62.7\%) completed this 12 -week trial.

\section{Dosing and concomitant medications}

At baseline, 38 out of the 67 (56.7\%) patients used medication for extrapyramidal symptoms (EPS), and 43 (64.2\%) patients used benzodiazepines or hypnotics. The frequencies of using antidepressants and mood stabilizers were 10 (14.9\%) and $7(10.4 \%)$, respectively. There were no significant changes in the usage or dosage of benzodiazepine, hypnotics, or EPS medications (data not shown).

The mean start and final doses of ziprasidone were $36.4 \pm$ $11.0 \mathrm{mg} /$ day (ranging from 20 to $80 \mathrm{mg} /$ day) and $101.5 \pm 47$ $\mathrm{mg} /$ day (ranging from 20 to $160 \mathrm{mg} /$ day), respectively. In the case of completers, the mean start and final doses were $35.7 \pm$ $8.3 \mathrm{mg} /$ day and $105.2 \pm 42.6 \mathrm{mg} /$ day, respectively. The patients' various daily doses of ziprasidone at 12 weeks were stratified

Table 1. Baseline characteristics of patients $(\mathrm{N}=67)$

\begin{tabular}{|c|c|}
\hline \multicolumn{2}{|l|}{ Sex, N (\%) } \\
\hline Men & $19(28.4)$ \\
\hline Women & $48(71.6)$ \\
\hline Age, mean (SD), y & $36.8(8.9)$ \\
\hline Education level, mean (SD), y & $12.6(2.5)$ \\
\hline \multicolumn{2}{|l|}{ Primary diagnosis, $\mathrm{N}$} \\
\hline Schizophrenic disorder & $62(92.5)$ \\
\hline Schizoaffective disorder & $5(7.5)$ \\
\hline Illness duration, mean (SD), y & $8.3(8.3)$ \\
\hline BPRS score, mean (SD) & $20.3(11.5)$ \\
\hline CGI-S score, mean (SD) & $3.5(1.0)$ \\
\hline GAF score, mean (SD) & $56.4(13.9)$ \\
\hline BMI, mean (SD), kg/m² & $25.8(4.2)$ \\
\hline \multicolumn{2}{|l|}{ Pre-switch antipsychotics, N (\%) } \\
\hline Amisulpride & $7(10.4)$ \\
\hline Aripiprazole & $12(17.9)$ \\
\hline Blonanserin & $4(6.0)$ \\
\hline Chlorpromazine & $1(1.5)$ \\
\hline Haloperidol & $1(1.5)$ \\
\hline Olanzapine & $10(14.9)$ \\
\hline Palliperidone & $19(28.4)$ \\
\hline Quetiapine & $3(4.5)$ \\
\hline Risperidone & $7(10.4)$ \\
\hline Zotepine & $3(4.5)$ \\
\hline
\end{tabular}

BPRS: Brief Psychotic Rating Scale, CGI-S: Clinical Global Impression, GAF: global assessment of functioning, BMI: Body Mass Index 
as follows: $1(2.4 \%)$ at $20 \mathrm{mg} /$ day, $4(9.5 \%)$ at $40 \mathrm{mg} /$ day, 2 $(4.8 \%)$ at $60 \mathrm{mg} /$ day, $13(31.90 \%)$ at $80 \mathrm{mg} /$ day, $2(4.8 \%)$ at $100 \mathrm{mg} /$ day, $8(19.0 \%)$ at $120 \mathrm{mg} /$ day, and $12(28.6 \%)$ at 160 $\mathrm{mg} /$ day.

\section{Effectiveness and tolerability}

The mean total scores on the BPRS significantly decreased from baseline $(20.3 \pm 11.5)$ to week $12(17.7 \pm 11.5, \mathrm{~F}=5.96, \mathrm{df}=$ 2.11, $\mathrm{p}=0.003$ ) (Figure 1). The changes in CGI-S scores from
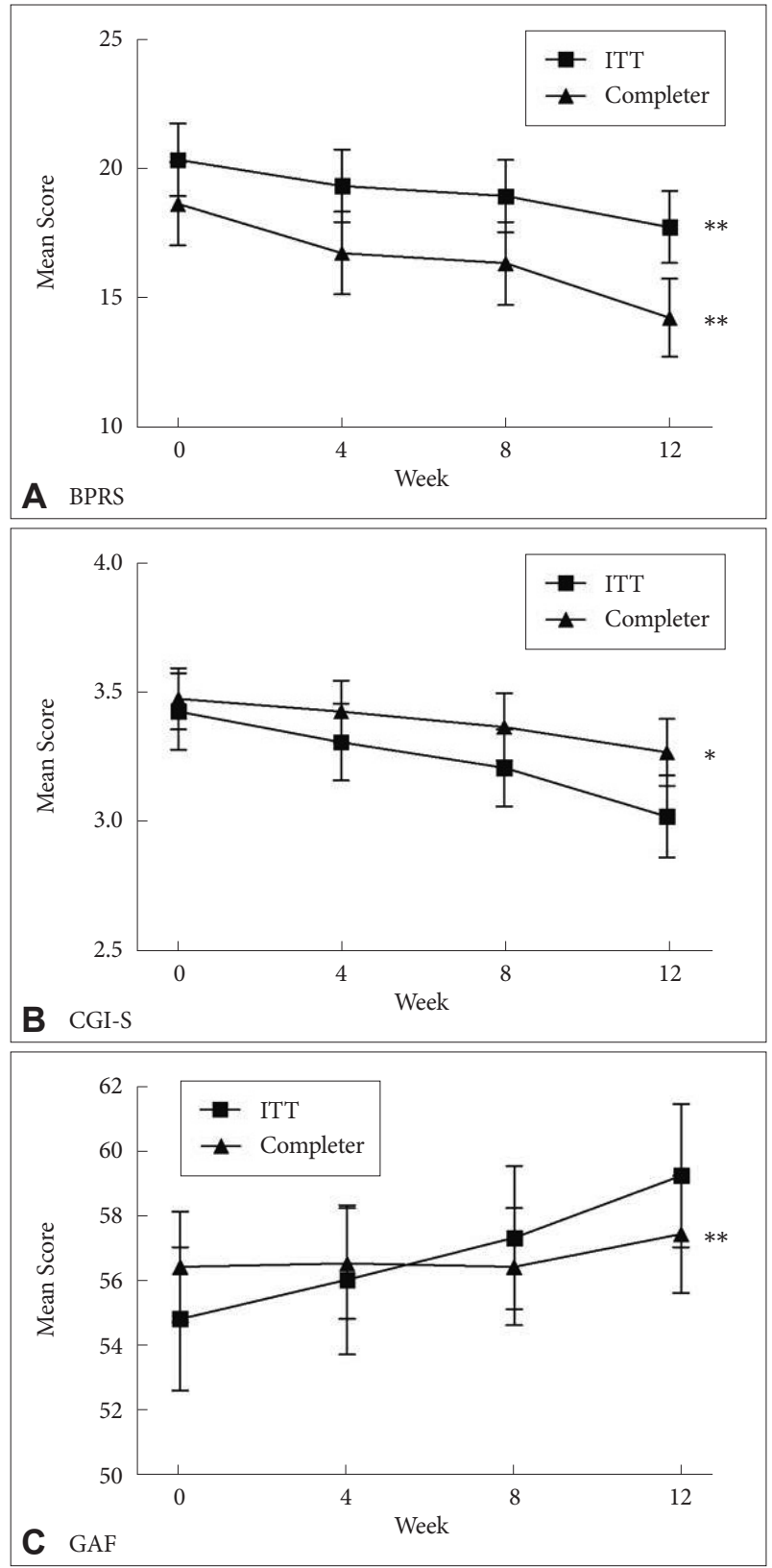

Figure 1. Mean change in the scores on BPRS, CGI-S, and GAF in both ITT sample and completers during switching to ziprasidone. ${ }^{*} p<0.05,{ }^{* *} p<0.01$. BPRS: Brief Psychotic Rating Scale, CGI-S: Clinical Global Impression, GAF: global assessment of functioning, ITT: Intent-To-Treat sample.
$3.5 \pm 1.0$ to $3.3 \pm 1.0$ were not statistically significant but did show evidence of a trend $(\mathrm{F}=2.65, \mathrm{df}=1.91, \mathrm{p}=0.07)$. There were no significant changes in the GAF scores. The completers showed significant changes in scores on the BPRS ( $F=9.87$, $\mathrm{df}=1.93, \mathrm{p}<0.001)$, CGI-S $(\mathrm{F}=5.20, \mathrm{df}=1.74, \mathrm{p}=0.01)$, and $\mathrm{GAF}$ $(\mathrm{F}=12.37, \mathrm{df}=1.65, \mathrm{p}<0.001)$.

We observed significant reductions in weight $(\mathrm{F}=6.90, \mathrm{df}=$ 1.91, $\mathrm{p}=0.002)$, BMI $(\mathrm{F}=8.53, \mathrm{df}=2.13, \mathrm{p}<0.001)$, and WHR $(\mathrm{F}=13.24, \mathrm{df}=2.60, \mathrm{p}<0.001)$ from baseline to the endpoint (Figure 2). The completers also showed significant reductions
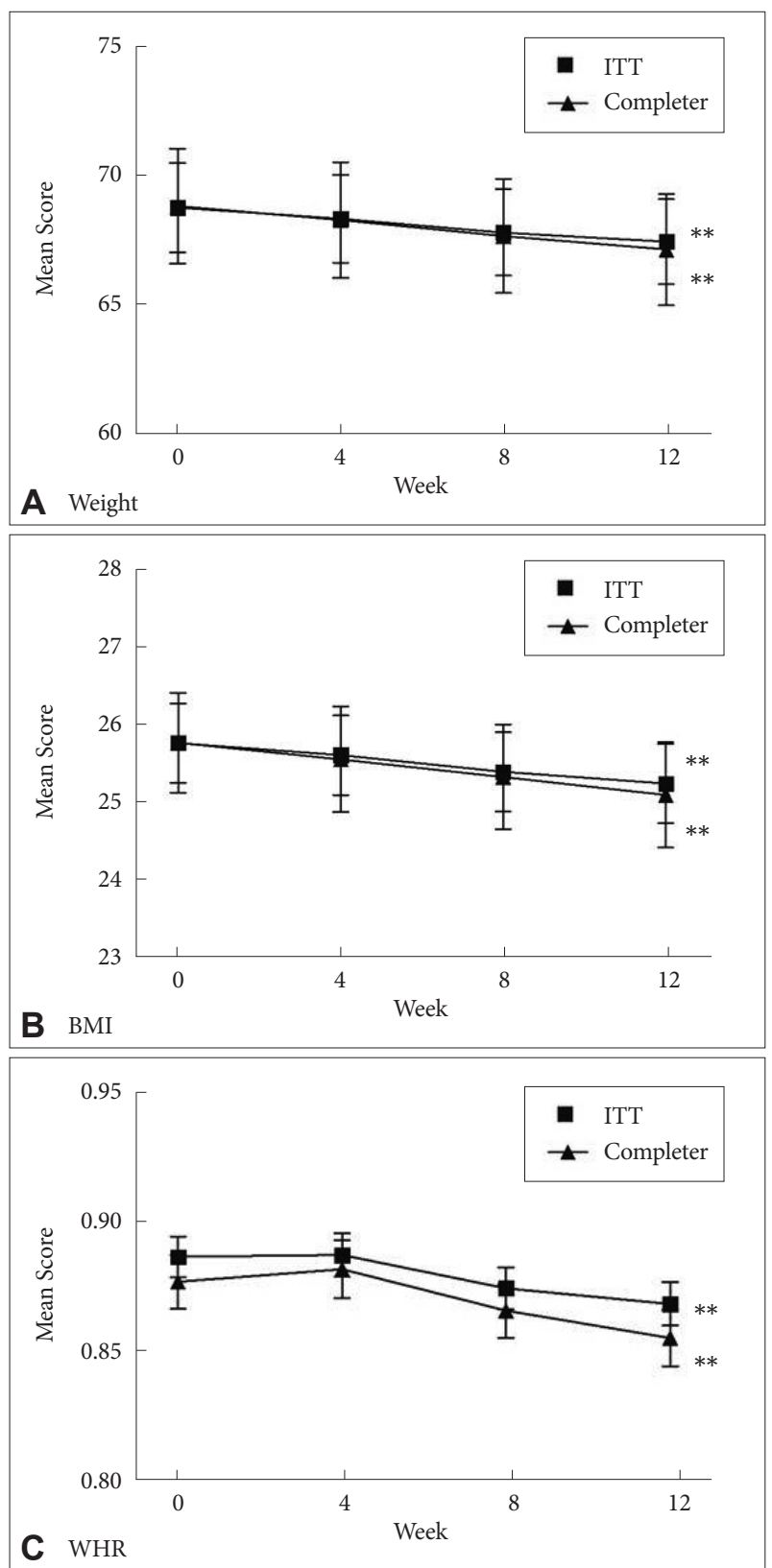

Figure 2. Mean change in the weight, BMI, and WHR in both ITT sample and completers during switching to ziprasidone. ${ }^{* *} \mathrm{p}<0.01$. BMI: Body Mass Index, WHR: Waist-to-Hip Ratio, ITT: Intent-ToTreat sample. 
in weight $(\mathrm{F}=5.39, \mathrm{df}=1.75, \mathrm{p}=0.009), \mathrm{BMI}(\mathrm{F}=6.97, \mathrm{df}=2.17$, $\mathrm{p}=0.001)$, and WHR $(\mathrm{F}=10.81, \mathrm{df}=2.49, \mathrm{p}<0.001)$.

Regarding the lipid profile, serum TG levels were significantly reduced from baseline $(143.9 \pm 101.7 \mathrm{mg} / \mathrm{dL})$ to the endpoint (123.3 $\pm 87.7 \mathrm{mg} / \mathrm{dL} ; \mathrm{F}=2.68, \mathrm{df}=3, \mathrm{p}=0.048)$; however, other lipid components did not significantly change over the study period (Figure 3). Among the completers, there was no significant change in the lipid profile over the study period.

There were no clinically significant changes in laboratory findings or ECGs over the study period. The side effects that were reported for at least $10 \%$ of the patients in at least one of the 4 visits during the treatment period are presented in Table 2. Side effects occurring at rates lower than $10 \%$ are not shown. The completers showed that the incidence of moderate-to-severe adverse events was significantly reduced from baseline $(2.3 \pm 3.2)$ to the endpoint $(1.5 \pm 2.6 ; \mathrm{t}=3.02, \mathrm{p}=0.004)$. The incidence of moderate-to-severe adverse events in the psychic and neurologic subgroups of the UKU-SERS-Pat was also reduced from baseline to the endpoint as follows: psychic from $0.9 \pm 1.6$ to $0.6 \pm 1.2(\mathrm{t}=2.01, \mathrm{p}=0.05)$; neurologic from $0.4 \pm 0.8$ to $0.1 \pm 0.4(\mathrm{t}=2.42, \mathrm{p}=0.02)$.

\section{DISCUSSION}

In this study, the BPRS scores were significantly decreased over a 12-week switch to ziprasidone, suggesting that the cross-tapering switching strategy can be useful for patients with schizophrenia. There are roughly four strategies that can be used when switching antipsychotics. ${ }^{6}$ First, abrupt discontinuation involves abruptly discontinuing prior antipsychotics and starting new antipsychotics. Second, prior antipsychotics can be slowly discontinued over several weeks. Third, prior antipsychotics can be tapered while simultaneously titrating new antipsychotics (the "overlapping" or "cross-over switching" strategy). Last, newly prescribed antipsychotics can be titrated and maintained at therapeutic doses while prior antipsychotics are also maintained at therapeutic doses for a period, which is called the "plateau" strategy. Each switching strategy has advantages and disadvantages. The abrupt discontinuation strategy minimizes drug-drug interactions but is prone to lead to withdrawal symptoms, whereas the plateau strategy has opposite effects to those of the abrupt strategy. Thus, it is important to apply an optimal switching strategy
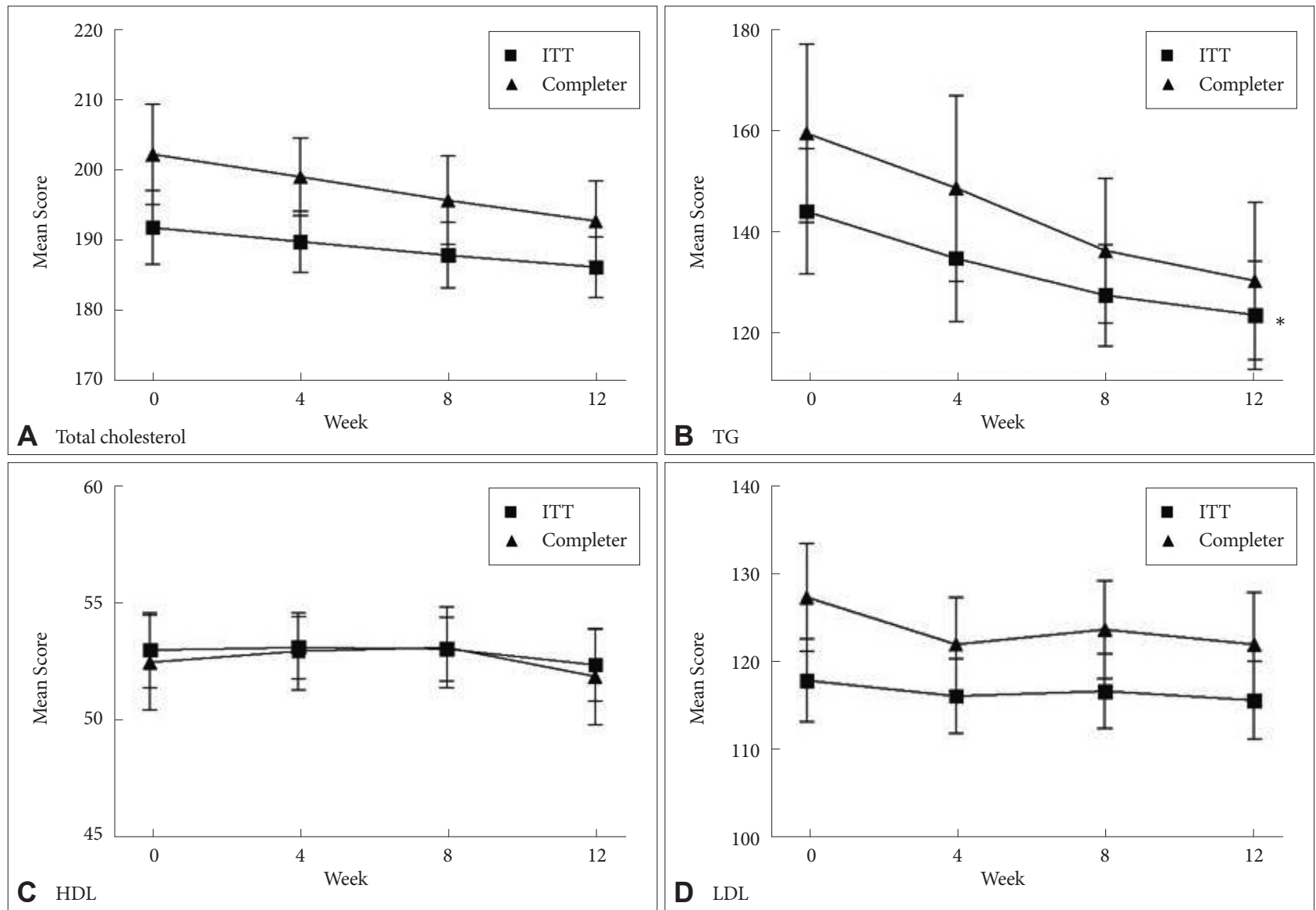

Figure 3. Mean change in the total cholesterol, TG, HDL, and LDL in both ITT sample and completers during switching to ziprasidone. ${ }^{*} p<0.01$. TG: triglyceride, HDL: high-density lipoprotein, LDL: low-density lipoprotein, ITT: intent-to-treat sample. 
Table 2. Moderate-to-severe adverse events with frequency $>10 \%$ during switching to ziprasidone

\begin{tabular}{|c|c|c|c|c|c|c|c|c|}
\hline & \multicolumn{2}{|c|}{$\begin{array}{c}\text { Baseline } \\
\mathrm{N}=67\end{array}$} & \multicolumn{2}{|c|}{$\begin{array}{c}\text { Week } 4 \\
N=60\end{array}$} & \multicolumn{2}{|c|}{$\begin{array}{c}\text { Week } 8 \\
N=48\end{array}$} & \multicolumn{2}{|c|}{$\begin{array}{c}\text { Week } 12 \\
\mathrm{~N}=42\end{array}$} \\
\hline & $\mathrm{N}$ & $\%$ & $\mathrm{~N}$ & $\%$ & $\mathrm{~N}$ & $\%$ & $\mathrm{~N}$ & $\%$ \\
\hline \multicolumn{9}{|l|}{ Psychic } \\
\hline Concentration difficulties & 9 & 13.5 & 9 & 15.0 & 6 & 12.5 & 5 & 11.9 \\
\hline Asthenia lassitude/increased fatigability & 10 & 14.9 & 9 & 15.0 & 4 & 8.3 & 3 & 7.1 \\
\hline Sleepiness sedation & 7 & 10.5 & 7 & 11.7 & 6 & 12.5 & 0 & 0 \\
\hline Depression & 9 & 13.4 & 6 & 10.0 & 3 & 6.3 & 4 & 9.5 \\
\hline Increased duration of sleep & 8 & 12.0 & 5 & 8.4 & 2 & 4.2 & 1 & 2.4 \\
\hline Reduced duration of sleep & 6 & 9.0 & 10 & 16.7 & 6 & 12.5 & 3 & 7.2 \\
\hline Increased dream activity & 8 & 12.0 & 2 & 3.3 & 3 & 6.3 & 0 & 0 \\
\hline \multicolumn{9}{|l|}{ Neurologic } \\
\hline Rigidity & 6 & 9.0 & 6 & 10.0 & 4 & 8.3 & 2 & 4.8 \\
\hline Akathisia & 8 & 12.0 & 5 & 8.3 & 5 & 10.5 & 1 & 2.4 \\
\hline \multicolumn{9}{|l|}{ Autonomic } \\
\hline Constipation & 6 & 9.0 & 6 & 10.0 & 5 & 10.5 & 4 & 9.5 \\
\hline \multicolumn{9}{|l|}{ Other } \\
\hline Amenorrhea & 8 & 12.0 & 6 & 10.0 & 3 & 6.3 & 4 & 9.5 \\
\hline Diminished sexual desire & 7 & 10.5 & 6 & 10.0 & 4 & 8.4 & 2 & 4.8 \\
\hline
\end{tabular}

according to the individual characteristics and pharmacological profiles of antipsychotics. Generally, it has been suggested that switching to antipsychotics with low affinities for histamine and cholinergic receptors will cause withdrawal symptoms. ${ }^{3}$ Ziprasidone exerts its therapeutic effects through antagonistic effects on the dopamine D2 and serotonin $2 \mathrm{~A}$ receptors as well as through reuptake inhibition of serotonin and norepinephrine transporters. ${ }^{10,11}$ Regarding tolerability, ziprasidone has less affinity for histaminergic, muscarinic, and adrenergic receptors than do other antipsychotics. Although the favorable tolerability profile of ziprasidone is beneficial for patients, slow tapering of previously administered antipsychotics is necessary to prevent withdrawal symptoms. Therefore, the cross-tapering strategy is a preferable switching strategy in terms of the pharmacological profile of ziprasidone and does not reduce its therapeutic efficacy. Previous studies with ziprasidone have principally used cross-tapering strategies, ${ }^{12-14}$ although some have used slow-tapering strategies. $^{15}$

Beyond supporting the effectiveness of the cross-tapering switching strategy, our study has several meaningful results with regard to switching antipsychotics to ziprasidone. First, we found that relatively low doses of ziprasidone were sufficient to exert therapeutic effects. A previous study using positron emission tomography suggested that ziprasidone doses greater than $120 \mathrm{mg} /$ day might be needed to exert a full therapeutic effect. ${ }^{16}$ Several clinical studies also have reported mean endpoint ziprasidone doses from 116 to $119 \mathrm{mg} /$ day. ${ }^{914}$ However, the mean dose of ziprasidone in our study was $101.5 \mathrm{mg} /$ day, which was substantially lower than what has been reported in previous studies. The result might be partially attributable to the rigorous inclusion criteria of this study, such as the absence of suicide risk, comorbidity, and substance-related problems, which are associated with poor prognosis in schizophrenia. ${ }^{17}$

Second, there were significant reductions in weight and waist circumference after switching to ziprasidone. Ziprasidone has been well-known for its favorable metabolic profile among antipsychotics, particularly atypical antipsychotics. Ziprasidone has a low affinity for histamine-1 (H1) and 5HT2C receptors, which have been implicated in increased appetite and consequent weight gain in patients. ${ }^{18,19}$ The significant reduction of TG levels reported in this study is in line with previous findings. ${ }^{9,13,18}$ In contrast to previous studies, however, other aspects of the lipid profile did not show significant changes. Such a finding suggests that the weight gain and central obesity-reducing effects of ziprasidone may be mediated by decreasing TG levels. Whereas several mechanisms are involved in central obesity and weight gain, elevated plasma TG levels have recently been viewed as a novel pathway to obesity. ${ }^{19}$ In an animal study, increased TG levels without changes in insulin and leptin resulted in hyperphagia after high-fat intake in rats. ${ }^{20}$ Future studies should further elaborate upon the underlying mechanisms by which plasma TG 
levels induce appetite and weight gain, although reduced TG levels could be attributable to the lack of anti-histaminergic effects of ziprasidone. ${ }^{21}$ However, the lower BMIs of the subjects compared to those reported in previous studies may also contribute these results. ${ }^{13,22}$

The drop-out rate of our participants was $37.3 \%$, which was somewhat higher than has been found in previous cross-tapering switching studies of 12 weeks duration (e.g., drop-out rates of 26-28\%). ${ }^{12-14}$ However, the drop-out rate due to side effects was $7.5 \%$ (five out of 67), which is comparable to previous studies (5-10\%). Consistent with previous studies, sleepiness was significantly improved after switching to ziprasidone. ${ }^{23}$ Additionally, a significant decrease in moderate-tosevere psychic and neurologic adverse events suggests that switching to ziprasidone is a useful strategy for patients with schizophrenia having tolerability issues.

In addition to its lack of a comparative group and relatively short intervention period, this study had several limitations. First, biological markers relevant to obesity and metabolic disturbances, such as fasting glucose, adiponectin, and cytokines, were not measured. Lipid dysregulation and central obesity, which were among the most improved factors in this study, are closely associated with inflammation. Previous studies have suggested that antipsychotics may influence the association between inflammatory and metabolic components. ${ }^{24}$ Thus, future studies should investigate interactions among those factors during ziprasidone treatment. Second, because a variety of antipsychotics were prescribed before switching to ziprasidone, it was not possible to identify the effects of the individual antipsychotics. Third, there were some discrepancies in the results between the ITT and completer groups. Over the study period, the CGI-S and GAF scores were significantly improved among completers, whereas there were no changes in the ITT group. Results such as these might arise if completers consist of patients with good adherence engaging in active treatment-seeking behaviors, thereby resulting in more favorable outcomes.

In summary, this study suggests that switching to ziprasidone using a cross-tapering strategy is effective and tolerable in patients with schizophrenia and schizoaffective disorder. In particular, this strategy may be helpful for the clinician who considers switching antipsychotics due to metabolic syndrome or EPS. Future studies with different switching strategies should be conducted to fully investigate which switching strategies would be most beneficial in patients with schizophrenia spectrum disorders in clinical practice.

\section{Acknowledgments}

This research was supported by the Soonchunhyang University Research Fund and Pfizer.

\section{REFERENCES}

1. Tandon R, Nasrallah HA, Keshavan MS. Schizophrenia, "just the facts" 5. Treatment and prevention. Past, present, and future. Schizophr Res 2010;122:1-23.

2. Lieberman JA, Stroup TS, McEvoy JP, Swartz MS, Rosenheck RA, Perkins DO, et al. Effectiveness of antipsychotic drugs in patients with chronic schizophrenia. N Engl J Med 2005;353:1209-1223.

3. Buckley PF Correll CU. Strategies for dosing and switching antipsychotics for optimal clinical management. J Clin Psychiatry 2008;69 Suppl 1:4-17.

4. Henderson DC. Managing weight gain and metabolic issues in patients treated with atypical antipsychotics. J Clin Psychiatry 2008;69:e04.

5. American Diabetes Association, American Psychiatric Association, American Association of Clinical Endocrinologists North American Association for the Study of Obesity. Consensus development conference on antipsychotic drugs and obesity and diabetes. Obes Res 2004; 12:362-368.

6. Lambert TJ. Switching antipsychotic therapy: what to expect and clinical strategies for improving therapeutic outcomes. J Clin Psychiatry 2007;68(Suppl 6):10-13.

7. American Psychiatric Association. Diagnostic and Statistical Manual of Mental Disorders, Fourth Edition. Washington DC: American Psychiatric Association; 1994.

8. Lindstrom E, Lewander T, Malm U, Malt UF, Lublin H, Ahlfors UG. Patient-rated versus clinician-rated side effects of drug treatment in schizophrenia. Clinical validation of a self-rating version of the UKU Side Effect Rating Scale (UKU-SERS-Pat). Nord J Psychiatry 2001;55 (Suppl 44):5-69.

9. Alptekin K, Hafez J, Brook S, Akkaya C, Tzebelikos E, Ucok A, et al. Efficacy and tolerability of switching to ziprasidone from olanzapine, risperidone or haloperidol: an international, multicenter study. Int Clin Psychopharmacol 2009;24:229-238.

10. Ballas C, Yang C, O’Reardon J, Ballas P, Baldassano C. Ziprasidone: a novel psychotropic with unique properties. Expert Rev Neurother 2004;4:179-186.

11. Stahl SM, Shayegan DK. The psychopharmacology of ziprasidone: receptor-binding properties and real-world psychiatric practice. J Clin Psychiatry 2003;64(Suppl 19):6-12.

12. Lublin H, Haug HJ, Koponen H, Sigmundsson T Kolb SA. Ziprasidone versus olanzapine, risperidone or quetiapine in patients with chronic schizophrenia: a 12-week open-label, multicentre clinical trial. World J Biol Psychiatry 2009;10:710-718.

13. Rossi A, Vita A, Tiradritti P, Romeo F. Assessment of clinical and metabolic status, and subjective well-being, in schizophrenic patients switched from typical and atypical antipsychotics to ziprasidone. Int Clin Psychopharmacol 2008;23:216-222.

14. Kim SW, Shin IS, Kim JM, Bae KY, Yang SJ, Yoon JS. Effectiveness of switching from aripiprazole to ziprasidone in patients with schizophrenia. Clin Neuropharmacol 2010;33:121-125.

15. Stip E, Zhornitsky S, Potvin S, Tourjman V. Switching from conventional antipsychotics to ziprasidone: a randomized, open-label comparison of regimen strategies. Prog Neuropsychopharmacol Biol Psychiatry 2010;34:997-1000.

16. Mamo D, Kapur S, Shammi CM, Papatheodorou G, Mann S, Therrien F, et al. A PET study of dopamine D2 and serotonin 5-HT2 receptor occupancy in patients with schizophrenia treated with therapeutic doses of ziprasidone. Am J Psychiatry 2004;161:818-825.

17. Altamura AC, Bobo WV, Meltzer HY. Factors affecting outcome in schizophrenia and their relevance for psychopharmacological treatment. Int Clin Psychopharmacol 2007;22:249-267.

18. Montes JM, Rodriguez JL, Balbo E, Sopelana P, Martin E, Soto JA, et al. Improvement in antipsychotic-related metabolic disturbances in patients with schizophrenia switched to ziprasidone. Prog Neuropsychopharmacol Biol Psychiatry 2007;31:383-388. 
19. Sorensen TI. Obesity defined as excess storage of inert triglycerides--do we need a paradigm shift? Obes Facts 2011;4:91-94.

20. Gaysinskaya VA, Karatayev O, Chang GQ, Leibowitz SF. Increased caloric intake after a high-fat preload: relation to circulating triglycerides and orexigenic peptides. Physiol Behav 2007;91:142-153.

21. Malmlof K, Golozoubova V, Peschke B, Wulff BS, Refsgaard HH, Johansen $\mathrm{PB}$, et al. Increase of neuronal histamine in obese rats is associated with decreases in body weight and plasma triglycerides. Obesity (Silver Spring) 2006;14:2154-2162.

22. Weiden PJ, Daniel DG, Simpson G, Romano SJ. Improvement in indi- ces of health status in outpatients with schizophrenia switched to ziprasidone. J Clin Psychopharmacol 2003;23:595-600.

23. Komossa K, Rummel-Kluge C, Hunger H, Schwarz S, Bhoopathi PS, Kissling W, et al. Ziprasidone versus other atypical antipsychotics for schizophrenia. Cochrane Database Syst Rev 2009:CD006627.

24. Na KS, Kim WH, Jung HY, Ryu SG, Min KJ, Park KC, et al. Relationship between inflammation and metabolic syndrome following treatment with paliperidone for schizophrenia. Prog Neuropsychopharmacol Biol Psychiatry 2012;39:295-300. 